\title{
Stress-activatedmiR-21/miR-21*in hepatocytes promotes lipid and glucose metabolic disorders associated with high-fat diet consumption
}

Calo, Nicolas ; Ramadori, Pierluigi ; Sobolewski, Cyril ; Romero, Yannick ; Maeder, Christine ;

Fournier, Margot ; Rantakari, Pia ; Zhang, Fu-Ping ; Poutanen, Matti ; Dufour, Jean-François ; Humar, Bostjan ; Nef, Serge ; Foti, Michelangelo

DOI: https://doi.org/10.1136/gutjnl-2015-310822

Posted at the Zurich Open Repository and Archive, University of Zurich ZORA URL: https://doi.org/10.5167/uzh-125968

Journal Article

Accepted Version

Originally published at:

Calo, Nicolas; Ramadori, Pierluigi; Sobolewski, Cyril; Romero, Yannick; Maeder, Christine; Fournier, Margot; Rantakari, Pia; Zhang, Fu-Ping; Poutanen, Matti; Dufour, Jean-François; Humar, Bostjan; Nef, Serge; Foti, Michelangelo (2016). Stress-activatedmiR-21/miR-21*in hepatocytes promotes lipid and glucose metabolic disorders associated with high-fat diet consumption. Gut:gutjnl-2015-310822.

DOI: https://doi.org/10.1136/gutjnl-2015-310822 


\section{Stress-activated $m i R-21 / m i R-21 *$ in hepatocytes promotes lipid and glucose metabolic}

disorders associated with high-fat diet consumption.

Nicolas Calo $^{1 *}$, Pierluigi Ramadori ${ }^{1 *}$, Sobolewski Cyril ${ }^{1}$, Yannick Romero ${ }^{2}$, Christine Maeder ${ }^{1}$, Margot Fournier ${ }^{1}$, Pia Rantakari ${ }^{3,4}$, Fu-Ping Zhang ${ }^{4}$, Matti Poutanen ${ }^{4}$, Jean-François Dufour $^{5}$, Bostjan Humar ${ }^{6}$, Serge Nef ${ }^{2}$, Michelangelo Foti ${ }^{1}$.

${ }^{1}$ Department of Cell Physiology and Metabolism and ${ }^{2}$ Department of Genetic Medicine and Development, Faculty of Medicine, University of Geneva, Switzerland. ${ }^{3}$ MediCity Research Laboratory, University of Turku, Finland. ${ }^{4}$ Department of Physiology and Turku Center for Disease Modeling, Institute of Biomedicine, University of Turku, Finland. ${ }^{5}$ Department of Surgery, University Hospital Zurich, Switzerland. ${ }^{6}$ Hepatology, Department of Clinical Research, University of Berne, Switzerland.

*Equal contribution

Correspondence: Michelangelo Foti, Dept. Cellular Physiology and Metabolism, CMU, 1 rue Michel-Servet, 1206 Geneva, Switzerland, Tel.: +41/22/3795204, Fax: +41/22/3795260, email: Michelangelo.foti@unige.ch

Keywords : miR-21; non-alcoholic fatty liver diseases; glucose metabolism; steatosis, adiposity.

Word count : 4054 


\section{ABSTRACT}

Objective: $m i R-21$ is an oncomir highly upregulated in hepatocellular carcinoma, but also in early stages of liver diseases characterized by the presence of steatosis. Whether upregulation of $m i R-21$ contributes to hepatic metabolic disorders and their progression towards cancer is unknown. This study aims at investigating the role of $m i R-21 / m i R-21 *$ in early stages of metabolic liver disorders associated with diet-induced obesity (DIO).

Design: Constitutive $m i R-21 / m i R-21 *$ knockout (miR21KO) and liver-specific $m i R-21 / m i R$ $21 *$ knockout $($ LImiR21KO) mice were generated. Mice were then fed with high-fat diet (HFD) and alterations of the lipid and glucose metabolism were investigated. Serum and exvivo explanted liver tissue were analyzed.

Results: Under normal breeding conditions and standard diet, $m i R-21 / m i R-21 *$ deletion in mice was not associated with any detectable phenotypic alterations. However, when mice were challenged with an obesogenic diet, glucose intolerance, steatosis and adiposity were improved in mice lacking $m i R-21 / m i R-21^{*}$. Deletion of $m i R-21 / m i R-21^{*}$ specifically in hepatocytes led to similar improvements in mice fed a HFD, indicating a crucial role for hepatic $m i R-21 / m i R-21^{*}$ in metabolic disorders associated with DIO. Further molecular analyses demonstrated that $m i R-21 / m i R-21 *$ deletion in hepatocytes increases insulin sensitivity and modulates the expression of multiple key metabolic transcription factors involved in fatty acid uptake, de novo lipogenesis, gluconeogenesis and glucose output.

Conclusion: Hepatic $m i R-21 / m i R-21 *$ deficiency prevents glucose intolerance and steatosis in mice fed an obesogenic diet by altering the expression of several master metabolic regulators. This study point out $m i R-21 / m i R-21^{*}$ as a potential therapeutic target for NAFLD and the metabolic syndrome. 


\section{SIGNIFICANCE OF THIS STUDY}

\section{What is already known about this subject?}

- Upregulation of $m i R-21$ expression is a general feature of tissue inflammation, fibrosis and of most human cancers including HCC.

- $m i R-21$ up-regulation occurs already in early stages of metabolic liver disorders and is associated with the presence of steatosis and insulin resistance in the liver of obese human, and of diet-induced rodent models of obesity.

- Bioinformatics analyses predict more than 2500 genes potentially regulated by $m i R$ $21 / m i R-21 *$ and more than $100 m i R-21 / m i R-21 *$ targets, not predicted by classical software, have been validated experimentally in different cells/tissues.

\section{What are the new findings?}

- Deletion of $m i R-21 / m i R-21 *$ is asymptomatic in mice bred in normal conditions.

- $m i R-21 / m i R-21 *$ in hepatocytes promotes systemic glucose intolerance, hepatic steatosis, hepatic insulin resistance and defects in hepatic gluconeogenesis, evoked by the consumption of an obesogenic diet.

- Hepatic $m i R-21 / m i R-21 *$ in mice fed an obesogenic diet alters directly, or indirectly, the expression of multiple master transcription factors regulating the lipid and glucose metabolism in hepatocytes.

\section{How might it impact on clinical practice in the foreseeable future?}

- $m i R-21 / m i R-21 *$ are promising therapeutic targets for the treatment of fatty liver disease with various etiological factors. 


\section{INTRODUCTION}

Non-alcoholic fatty liver disease (NAFLD) represents the liver manifestation of metabolic disorders associated with obesity and diabetes.[1] Hepatic steatosis characterized by abnormal accumulation of lipid droplets in hepatocytes is the hallmark of NAFLD. Although the molecular mechanisms are still unclear, steatosis is often associated with insulin resistance (IR) and glucose intolerance, and can evolve to steatohepatitis and fibrosis with time.[2] Since hepatocellular carcinoma (HCC) might also occur as an end stage of NAFLD, these hepatic metabolic disorders could also be regarded as preneoplastic states of the liver. In this regard, alterations of glucose metabolism, e.g. increased glycolysis and energy production,[3] and deregulation of fatty acid/cholesterol metabolism, i.e. excessive lipid anabolism and storage, are now increasingly recognized to promote liver carcinogenesis.[4]

Epigenetic mechanisms, in particular driven by microRNAs (miRNAs), play a major role in complex metabolic processes including insulin and glucose homeostasis, cholesterol and lipid metabolism, energy expenditure, adipogenesis and inflammation.[5, 6] MicroRNAs are short non-coding RNAs regulating gene expression either through the induction of specific mRNA targets degradation or by inhibiting their translation.[7] Interestingly, miRNAs expression is tissue-specific and may vary according to the metabolic requirements of the cell/organ.[8] Consequently, deregulation of miRNAs expression is often associated with metabolic disorders.[6]

A wealth of studies has indicated that deregulated expression of specific hepatic miRNAs critically contributes to the development of liver-specific metabolic disorders, insulin resistance and cancer.[9, 10, 11, 12] Among them, $m i R-21(m i R-21-5 p)$ is an oncomir highly up-regulated in most of the cancers examined so far.[13] Of importance, although miR-21 is highly expressed in hepatocytes, it is minimally active in normal physiological 
conditions.[14] However, in pathological conditions, levels of active miR-21 are increased and its activity importantly contributes to molecular alterations triggering hepatic disorders. For example, increased miR-21 expression might play an important role in liver fibrosis, consistent with previous studies examining the role of miR-21 in kidney, heart and lung fibrosis.[15, 16, 17, 18, 19, 20] In cholangiocarcinoma and HCC, miR-21 is up-regulated, thereby inhibiting the expression of crucial tumour suppressors and favoring hepatic cells survival.[19, 21, 22, 23, 24] miR-21 also regulates early phases of liver regeneration following partial hepatectomy.[25, 26] Finally, the complementary passenger strand of $m i R-21$ (miR$21 *$ or $m i R-21-3 p)$, which normally undergoes degradation, was previously reported to be upregulated and to exert some functions in renal fibrosis and cardiac hypertrophy.[27, 28, 29] Interestingly, we and others have reported that $m i R-21$ up-regulation occurs already in early stages of metabolic liver disorders and is associated with the presence of steatosis in the liver of obese human and of diet-induced rodent models of obesity.[30, 31, 32] Considering the concept where the hepatic metabolic reprogramming promotes inflammation and fibrosis and sustains oncogenic transformation, we generated conditional $m i R-21 / m i R-21 *$ knockout mice to delineate in vivo the role of $m i R-21 / m i R-21 *$ in alterations of hepatic lipid and glucose metabolism associated with consumption of fat-enriched diet. We selected this approach rather than using synthetic $m i R-21$ or $m i R-21 *$ inhibitors given the reported discrepant results obtained with genetic models of $m i R-21 / m i R-21 *$ deletion or administration of synthetic $m i R$ 21 inhibitors, in heart pathology for example.[33] Herein, we show that $m i R-21 / m i R-21$ * expression in hepatocytes promotes systemic glucose intolerance, hepatic steatosis and defects in hepatic gluconeogenesis, evoked by the consumption of an obesogenic diet. Evidence is provided that, in mice fed an obesogenic diet, hepatic $m i R-21 / m i R-21$ * directly and indirectly regulates the expression of multiple master transcription factors regulating lipid and glucose metabolism in hepatocytes. 


\section{MATERIALS AND METHODS}

\section{Reagents}

All reagents, devices, buffers, primers, culture media, kits, antibodies and diets are described in the Supplementary Materials and Methods.

\section{Animals}

We first generated $m i R-21^{l o x / l o x}$ mice where the 260 bp sequence containing the mir 21 gene was flanked with two loxP sites via homologous recombination in ES cells using standard techniques (Supplementary Fig. S1A). Constitutive miR-21 knockout animals were obtained by crossing mice carrying two $m i R-2 l^{l o x}$ alleles with a transgenic mice expressing the Cre recombinase under the control of a male germ cell-specific promoter ( $\mathrm{d} d x 4$-Cre transgene). Male $D d x 4-C r e ; m i R-21^{l o x / l o x}$ mice were then used to produce animals with constitutive wholebody $m i R-21 \mathrm{KO}$ alleles (miR21KO mice). To achieve selective inactivation of $m i R-21$ in hepatocytes, we mated $m i R-21^{l o x / l o x}$ mice with $A l b-C r e-E R^{T 2}$ transgenic mice expressing Cre$\mathrm{ER}^{\mathrm{T} 2}$ recombinase under the control of the albumin promoter,[34] a kind gift of Prof. D. Metzger and Prof. P. Chambon (University of Strasbourg, France). Although some leakage of the Cre activity was observed in hepatocyte as previously described,[35, 36] total recombinase activity was induced by subcutaneous administration of tamoxifen pellets ( $25 \mathrm{mg} / \mathrm{tablet})$ at 2 months of age, to fully delete the $m i R-21$ alleles specifically in hepatocytes (LImiR21KO mice). All studies were carried out using mice with mixed genetic background (C57BL/6Ncr, 129S6), and miR-21 deletion was confirmed by conventional PCR-based genotyping and qRT-PCR for mature $m i R-21$. The detailed protocols used to generate each mouse strain, and for their genotyping, are described in the Supplementary Materials and Methods. 
Control miR-2 $1^{\text {lox/lox }}$ mice (CTRL) and miR21KO mice were fed standard diet and tap water ad libitum until the age of two months. Mice of each strain were then randomly organized into two groups $(n=5-10)$ and submitted to a 4 weeks-long feeding period with high-fat diet (HFD: $60 \% \mathrm{cal} / \mathrm{fat}$ ) or standard diet (CD: $5 \% \mathrm{cal} / \mathrm{fat}$ ), matched for its composition with the HFD. CTRL and LImiR21KO mice were submitted to the same CD and HFD after tamoxifen administration. Food intake and body weight were monitored daily. At the end of the study, mice were euthanized, and blood and organs were collected. Animal care and experimental procedures were performed in accordance with the Swiss guidelines for animal experimentation and ethically approved by the Geneva Health head office.

\section{Metabolic phenotyping and EchoMRI}

Metabolic phenotyping of mice was performed for 72 hours using metabolic cages after 5 days of adaptation prior of recording. EchoMRI was used to measure total fat and lean body mass.

\section{Glucose/pyruvate tolerance tests}

Glucose tolerance test (GTT) and pyruvate tolerance test (PTT) were performed as previously described.[37] Briefly, mice were starved overnight and a glucose load of $1.5 \mathrm{~g} / \mathrm{kg}$, or a pyruvate load of $2 \mathrm{~g} / \mathrm{kg}$, was administered i.p. Blood samples were collected, and glucose levels measured using a glucometer.

\section{Histology}

Liver samples were fixed in $4 \%$ paraformaldehyde and $6-\mu \mathrm{m}$-thick sections were stained with hematoxylin/eosin (H\&E) for morphological investigations. Oil Red O (ORO) staining was 
performed on 6- $\mu \mathrm{m}$-thick cryo-sections to stain neutral lipids. Morphometric analysis of ORO staining was performed using the MetaMorph ${ }^{\circledR}$ software on at least 6 different fields of view per slide (> 30000 lipid droplets/sample).

\section{Tissues and plasma analyses}

Plasma levels of triglycerides (TG), cholesterol and glucose were determined by an automated analyzer. Lipid extraction from cryo-preserved hepatic samples was performed by chloroform/methanol extraction. TG and free cholesterol/cholesterol esters contents were measured by colorimetric enzymatic assays with commercial kits.

\section{Quantitative Real-Time PCR (qRT-PCR)}

RNA was extracted with Trizol reagent and $1 \mu \mathrm{g}$ was used for cDNA synthesis. PCR was performed with SYBR Green and Cyclophilin A (Ppia) was used to normalize gene expression. Primers sequences are listed in Supplementary Materials. For miRNA analysis, 10 ng of total RNA was used for miRNA-specific cDNA synthesis with TaqMan MicroRNA RT kit and PCR was performed with Taqman MicroRNA Assays. U6/Sno202 were used to normalize $m i R-21$ expression.

\section{Western Analyses}

Tissues and cells were lysed in ice-cold RIPA buffer. Equal amounts of proteins were resolved by $5-20 \%$ gradient SDS-PAGE and blotted to nitrocellulose membranes. Proteins were detected with specific primary antibodies and HRP-conjugated secondary antibodies using ECL. 


\section{Isolation of primary mouse hepatocytes (PMH)}

PMH were isolated by collagenase perfusion of the liver, as previously described.[38] Cells $\left(6.25 \times 10^{4} / \mathrm{cm}^{2}\right)$ were seeded 6 hours in PMH medium and then starved overnight of FCS and insulin prior to insulin stimulation $\left(10^{-8} \mathrm{M}, 15 \mathrm{~min}\right)$.

\section{Bioinformatic predictions and Statistical Analysis}

Predictions of $m i R-21 / m i R-21 *(m m u-m i R-21-5 p / m m u-m i R-21-3 p)$ targets were performed using the miRWalk2.0 atlas [39] allowing simultaneous predictions of miRNA targets for the DIANA-microTv4.0, DIANA-microT-CDS, miRanda-rel2010, mirBridge, miRDB4.0, miRmap, miRNAMap, doRiNA, PicTar2, PITA, RNA22v2, RNAhybrid2.1 and Targetscan6.2 algorithms. Only targets predicted by at least 6 programs were kept in consideration.

Data are expressed as mean \pm SEM. Statistical significances were assessed by 2-way ANOVA for GTT/PTT experiments and Welch's t-tests on $\log _{2}$-transformed (ratios) or untransformed values for other experiments. Differences were considered significant when $* \mathrm{p}<0.05$, $* * \mathrm{p}<0.01$ or $* * * \mathrm{p}<0.001$ 


\section{RESULTS}

\section{Metabolic phenotype of miR21KO mice}

To confirm deletion of $m i R-21 / m i R-21 *$ in the miR21KO mice, we measured mature $m i R-21$ transcript level in the liver. Ablation of a $260 \mathrm{bp}$-long fragment including the $m i R-21$ gene located in the 3'UTR of the Tmem49/Vmp-1 gene resulted in undetectable level of mature $m i R-21$ transcripts (fig. S1A-B), and its passenger strand $m i R-21^{*}$, but did not affect Tmem49/Vmp-1 mRNA expression (supplementary figure S1C). Under standard chow diet (CD), miR21KO mice did not display any evident morphologic, metabolic or behavioural phenotype, except a slight but significant difference in fat versus lean mass body composition (figure $1 \mathrm{~A}-\mathrm{B}$ ). In these conditions, $m i R-21 / m i R-21 *$ deletion did not trigger upregulation of previously in vitro validated miR-21 targets (figure S1D), consistent with the recently reported inactive state of hepatic $m i R-21 / m i R-21^{*}$ under physiological conditions.[14] However, after 4 weeks of high fat-containing diet (HFD), the ratio of lean versus fat mass was further increased in miR21KO as compared to CTRL mice (figure 1A-B). Although total body weight and food intake were unchanged, Labmaster analyses indicated that $\mathrm{O}_{2}$ consumption, $\mathrm{CO}_{2}$ and heat production were significantly increased together with water intake in mice under HFD in the absence of $m i R-21 / m i R-21 *$ (figure $1 \mathrm{C}-\mathrm{E}$ ) thereby suggesting an enhanced energy expenditure.

\section{Constitutive $m i R-21 / m i R-21 *$ deficiency improves glucose and lipid metabolism in mice}

\section{fed a HFD}

Glucose tolerance tests (GTT) were performed in mice fed a CD or HFD to evaluate the impact of $m i R-21 / m i R-21 *$ deficiency on glucose tolerance. Although fed/fasted glycemia was similar between CTRL and miR21KO mice (data not shown), glucose intolerance 
associated with HFD was significantly ameliorated in miR21KO mice (figure 2A). The liver importantly contributed to this improved glucose tolerance, since hepatic glucose production was strongly decreased in response to a pyruvate challenge (PTT, Pyruvate Tolerance Test) in miR21KO mice fed the HFD (figure 2B). $m i R-21 / m i R-21 *$ deficiency deeply impacted also the hepatic lipid metabolism of mice stressed with HFD. Liver weights and ratios to body weights were similar in CTRL and miR21KO mice (figure 2C). However, hepatic steatosis associated with HFD consumption was significantly reduced in miR $21 \mathrm{KO}$ mice as assessed by histological analyses of H\&E stained liver sections and a decreased content of hepatic triglycerides (TG) but not cholesterol esters (figure 2D-E). Finally, TG and cholesterol levels in the sera of miR21KO mice also diminished, although not significantly for circulating TG (Supplementary figure S2A).

Together these data indicate that constitutive deletion of $m i R-21 / m i R-21^{*}$ attenuated systemic and hepatic metabolic disorders in mice challenged with a HFD.

Deletion of $m i R-21 / m i R-21 *$ specifically in hepatocytes is sufficient to improve glucose metabolism in mice challenged with HFD

To further delineate the role of hepatic $m i R-21 / m i R-21 *$ in DIO-associated metabolic disorders, we generated hepatocyte-specific inducible $m i R-21 / m i R-21 *$ knockout mice (LImiR21KO). As shown in Supplementary figure S3, miR-21 deletion was observed specifically in the liver and not in other organs. Similar to that observed with miR21KO mice, LImiR21KO mice fed with HFD for 4 weeks displayed increased glucose tolerance and reduced hepatic glucose production in response to pyruvate (figure $3 \mathrm{~A}$ ), whereas mice fed a CD displayed only a weak inhibition of glucose output in response of a pyruvate challenge (Supplementary figure S4). Gene and protein expression of major transcriptionally regulated effectors controlling glucose turnover and output in the liver were further analysed in 
LImiR21KO mice fed a HFD. A significant decrease in the expression of major glycolytic enzymes (Gck, Pdkl, Pkfl and Pklr) and of those promoting gluconeogenesis (Klfl5 and G6PC) was observed consistent with decreased glycolytic fluxes and reduced gluconeogenesis and glucose output in the absence of $m i R-21 / m i R-21^{*}$ (figure 3B-C). Western analyses of hepatic insulin signalling effectors in unstimulated liver extracts indicated a $>2$-fold increase of insulin receptor substrate 2 (IRS2) expression associated with significant increase in AKT phosphorylation on Ser473 and Rictor expression in LImiR21KO as compared to CTRL mice (figure 3D). In primary mouse hepatocytes (PMH) isolated from CTRL and LImiR21KO fed a HFD, phosphorylation of Akt on both Thr308 and Ser473 was also significantly increased by $m i R-21 / m i R-21 *$ deficiency upon insulin stimulation (figure $3 \mathrm{E})$.

These results indicate that hepatic $m i R-21 / m i R-21^{*}$ alter systemic glucose tolerance and hepatic insulin sensitivity, gluconeogenesis and glucose output under stress conditions such as high fat feeding.

\section{Hepatic fatty acid uptake and lipogenesis are regulated by $m i R-21 / m i R-21 *$ in mice fed a HFD}

As we observed with miR21KO mice, LImiR21KO mice fed a HFD had a higher ratio of lean versus fat mass body composition although their body and liver weight were similar to CTRL mice (figure 4A). However, hepatic steatosis, which was already severe after 4 weeks of HFD in CTRL mice, was strongly reduced in LImiR $21 \mathrm{KO}$ mice, as assessed by histological staining and quantification of hepatic neutral lipid by H\&E and Oil red $\mathrm{O}$, and by measuring TG and cholesterol esters contents in hepatic tissues (figure 4B). To gain insights into the mechanisms by which $m i R-21 / m i R-21 *$ deficiency prevents steatosis development with high fat feeding, we evaluated the expression of major rate limiting enzymes regulating hepatic 
lipid metabolism. Expression of hepatic genes regulating cholesterol metabolism, fatty acid oxidation, esterification, intracellular transport, export and lipolysis were poorly affected by the absence of $m i R-21 / m i R-21 *$ (figure S5). In contrast, important factors promoting fatty acid uptake and lipogenesis in hepatocytes were significantly downregulated in LImiR21KO mice under HFD, both at the mRNA and protein levels. In particular, expression of CD36, Fatpl and FAS, were strongly decreased, whereas the inhibitory phosphorylation of ACC increased (figure 4C-E).

Together, these data indicate that absence of $m i R-21 / m i R-21 *$ in hepatocytes of mice fed an obesogenic diet restrains steatosis development by reducing both lipogenesis and fatty acid uptake in hepatocytes.

$m i R-21 / m i R-21 *$ activity in hepatocytes affects multiple key factors involved in metabolic transcriptional regulation of hepatic glucose and lipid metabolism

The hepatic regulation of lipid and glucose metabolism is under the control of several master transcriptional regulators acting intricately in complex networks. Among those, several are predicted as direct targets of $m i R-21 / m i R-21 *$ through bioinformatics analyses and/or have been experimentally validated as $m i R-21 / m i R-21 *$ targets (figure $5 \mathrm{~A}-\mathrm{B}$ ). Expression of potential $m i R-21 / m i R-21 *$-targeted transcription factors, possibly associated with the phenotype of LImiR21KO mice stressed by a HFD, were investigated at the mRNA and protein levels. Consistent with increased insulin sensitivity and a reduced fatty acid uptake, de novo lipogenesis, gluconeogenesis and glucose output in hepatocytes, the protein expression of FOXO1, FOXA2, INSIG2, STAT3, and HNF4- $\alpha$ was significantly increased in LImiR21KO mice fed a HFD (figure 5C), whereas expression of PPAR- $\gamma$ and active SREBP1C were importantly reduced (figure 5D). Interestingly, protein expressions were not always reflected at the mRNA levels suggesting a translational repression by $m i R-21 / m i R-21$ * 
of the mRNAs of specific factors (e.g. FOXO1, FOXA2, STAT3, and HNF4- $\alpha$. As expected with increased levels of INSIG2, expression of active SREPB1C was significantly reduced in LImiR21KO mice fed a HFD consistent with the reduced FAS levels and lipogenesis (figure 4). Finally, although PPAR- $\alpha$ was previously described as a $m i R-21$ target in vitro,[40, 41] its expression only slightly tends to increase in the liver of LImiR21KO mice and $\beta$-oxidation seems not to be stimulated, even slightly decreased as shown in Supplementary figure S5F.

These data indicate that $m i R-21 / m i R-21 *$ activity induced by HFD stress in hepatocytes leads directly and/or indirectly to combined alterations of multiple master metabolic factors regulating hepatic glucose and lipid metabolism. 


\section{DISCUSSION}

In this study, we provide in vivo evidence that $m i R-21 / m i R-21^{*}$ are necessary factors for glucose intolerance and fatty liver disease in mice challenged with a HFD. Importantly, genetic deletion of $m i R-21 / m i R-21 *$ in all tissues, or specifically in hepatocytes, led to similar improvements of metabolic disorders associated with high fat feeding in mice, thereby outlining the critical role of hepatocellular $m i R-21 / m i R-21 *$ for metabolic homeostasis. Our data further suggest that HFD-associated $m i R-21 / m i R-21 *$ activity leads to a complex alteration associated with glucose intolerance and steatosis in mice of multiple key transcriptional factors in hepatocytes controlling lipid and glucose metabolism.

miR-21 is a highly expressed miRNA in the liver [42] and is further up-regulated with obesity,[30, 31, 32, 43, 44] steatohepatitis and fibrosis,[18, 31] as well as in cholangiocarcinoma and HCC.[21, 22] Actually, hundreds of miRNAs have been shown to be deregulated in human NAFLD, steatohepatitis and diabetes, each of them potentially controlling different and multiple aspects of hepatocyte biology, such as insulin sensitivity, lipid and glucose metabolism, ER and oxidative stresses, cell apoptosis and survival.[45, 46, 47] Complexity in investigating the metabolic role of $m i R-21 / m i R-21^{*}$ arises from the fact that $m i R-21 / m i R-21^{*}$ appears to be inactive, although highly expressed, in the liver of mice bred in normal conditions.[14] Consistent with this concept, we could not detect any major phenotypic abnormalities under normal conditions in mice bearing a constitutive or liverspecific deletion of $m i R-21 / m i R-21^{*}$. , Therefore, our data further highlight the role of $m i R$ $21 / m i R-21 *$ in hepatocytes as a stress microRNA promoting the onset of liver disorders upon metabolic challenge.

Based on bioinformatics prediction analyses (miRwalk analyses) more than 1300 and 2500 genes are potentially regulated by $m i R-21$ and $m i R-21 *$ respectively (Supplementary figure 
S6). In addition, more than $100 \mathrm{miR}-21 / \mathrm{miR}-21 *$ targets, not predicted by classical software, have been validated experimentally in different cells/tissues further highlighting the complexity and limits of prediction algorithms for microRNAs of stress like $m i R-21 / m i R$ $21 *$.[14] Finally, the regulatory functions of $m i R-21 / m i R-21 *$ are likely cell/tissue specific, of weak amplitudes, but exerted on multiple genes involved in intricate molecular networks regulating different cellular processes.[24, 48] Based on these considerations, it is unlikely that the beneficial effects of $m i R-21 / m i R-21 *$ deletion in hepatocytes of mice challenged with an obesogenic diet result from modulation of only a single pathway. Consistent with this concept, our data indicate that several important transcriptional regulators of the hepatic lipid and glucose metabolism, predicted or experimentally validated targets of $m i R-21 / m i R-21^{*}$, are significantly affected by deletion of $m i R-21 / m i R-21 *$ in mice fed a HFD. Similar deregulation of complex transcriptional networks by $m i R-21$ was also previously reported by global gene expression profile in liver cancer cells.[24] Restoring the expression and activity of all these $m i R-21 / m i R-21 *$-dependent key factors deregulated in the liver of LImiR21KO mice fed a HFD (i.e. FOXO1,[49] FOXA2,[50] SREBP1C,[50] STAT3,[51] INSIG2 and HNF4- $\alpha$ )[52] to similar levels than those in CTRL mice fed a HFD is technically very challenging. Alternatively, complete inhibition of a candidate target of $m i R-21 / m i R-21^{*}$, through genetic deletion or pharmacological inhibition, can lead to cellular effects greatly exceeding the fine regulation of these factors by microRNAs. Such experimental approaches may therefore lead to over-interpretation of the respective role of a single potential target, or combination of them, deregulated by activated $m i R-21 / m i R-21 *$ Based on our data, a hypothetical model of complex interactive networks involving potential $m i R-21 / m i R-21 *$ targets and their role in regulating the hepatic metabolism is proposed in figure $5 \mathrm{E}$. 
miR-21-dependent PPAR- $\alpha$ downregulation in hepatic biliary and inflammatory cells was reported by Loyer et al as to induce inflammation and fibrosis in a mouse model of atherosclerosis (LDLRKO mice) or in mice fed a MCD diet.[53] We could not detect significant alterations of PPAR- $\alpha$ expression in LImiR21KO mice fed a HFD and expressions of enzymes promoting fatty acids oxidation, a process usually stimulated by PPAR- $\alpha$ activity, were decreased.[54] Therefore our data do not favour a role for $m i R$-21-dependent PPAR- $\alpha$ downregulation in hepatocytes that could affect fatty acids oxidation and trigger steatosis. These differences between our study and the one by Loyer et al., in which different mouse models and approaches to inhibit $m i R-21$ are used, underline the complexity of $m i R-21 / m i R$ $21^{*}$ target network, the cell-specific and context-dependent effects of $m i R-21 / m i R-21^{*}$, as well as the importance of the experimental approaches used to understand the biological functions of $m i R-21 / m i R-21^{*}$.

Most of metabolic improvements observed in LImiR21KO mice were actually consistent with the drastic downregulation at the mRNA and protein level of PPAR- $\gamma$. The decreased expression of PPAR- $\gamma$, which is not predicted as a $m i R-21 / m i R-21 *$ target, could results from the combined effects of FOXO1 and HNF4- $\alpha$, which both can inhibit PPAR- $\gamma$ but through distinct mechanisms (figure 5D).[55, 56] On the other hand, lipogenesis can also be impaired in LImiR21KO mice fed a HFD through the upregulation of INSIG2, a predicted target of $m i R-21 / m i R-21 *$ and a negative regulator of SREBP1C.[57] Considering the capability of $m i R-21$ to affect the expression of several target genes, the discrimination between direct and indirect effects modulating the downstream genes is complex, in particular in vivo. However, from our analyses, it is likely that the beneficial impact of hepatic miR-21 genetic deletion on diet-induced metabolic disorders, is not associated with modulation of a single $m i R-21$, or $m i R-21^{*}$, target only, but instead is the consequence of fine and concerted alterations in the expression of multiple hepatocyte-specific genes. 
While preparing this manuscript, we also became aware of a study by $\mathrm{Wu}$ et al.,[44] who described a mechanism involving a HBP1-P53-SREBP1C pathway in the control of dietinduced steatosis development by $m i R-21$. To this end, they used synthetic inhibitors of miR21 in vivo in mice and in vitro in HepG2 cultured cells.[44] In contrast to Wu et al., we did not detect up-regulation of HBP1 and only a weak increase $(\approx 30 \%)$ of p53 mRNA expression in mice genetically deleted for $m i R-21 / m i R-21 *$ specifically in hepatocytes and fed a HFD, indicating that alternative mechanisms take place in our model. Discrepant results obtained with genetic models of $m i R-21 / m i R-21 *$ deletion or administration of synthetic $m i R-21$ inhibitors have already been reported in studies investigating heart pathology for example.[33] As well, transformed hepatoma cells (e.g. HepG2 cells) express different protein profile, multiple mutations and highly active $m i R-21$ as compared to primary hepatocytes, which may lead to different conclusions regarding pathophysiological mechanisms occurring in vivo.[58] All together, these considerations suggest cautiousness in interpretation of data obtained with the pharmacological inhibitors of single-stranded microRNAs.[33] In our study, we bypass these potential issues by generating constitutive global $m i R-21$ knockout mice (miR21KO) and liver-specific miR-21 KO mice (LImiR21KO) to analyze metabolic defects induced by high fat feeding. LImiR21KO mice are the first mice genetically engineered to knockout specifically $m i R-21 / m i R-21 *$ in hepatocytes. Furthermore, the total lack of the gene results not only in undetectable levels of mature $m i R-21$, but also in the loss of the passenger strand, $m i R-21^{*}$, which might influence the observed phenotype.[27, $28,29]$

Regarding the enhanced hepatic insulin sensitivity in $m i R-21 / m i R-21 *$-deficient mice, it could results from a decreased hepatic steatosis as previously suggested.[59] Additionally, the direct modulation of predicted target genes like STAT3 or RICTOR, or indirect targets like IRS2, induced by the loss of $m i R-21 / m i R-21 *$ might also lead to an improved insulin signalling.[60, 
61, 62] In particular, and contrary to that previously described in keratinocytes and adipocytes, $[63,64]$ loss of $m i R-21 / m i R-21 *$ resulted in an increased hepatic phosphorylation of AKT that did not display evident correlation to PTEN levels. It is also of interest that the specific down-regulation of G6PC in $m i R-21 / m i R-21 *$-deficient mice fed a HFD could be mediated indirectly by STAT3-dependent mechanisms.[65] Since STAT3 is a predicted miR21 target gene, it may also regulate some of the metabolic processes altered by the HFD. Of note, miR-21-dependent modulation of STAT3 could also represent a potential mechanisms contributing to the inflammatory response pushing simple steatosis towards steatohepatitis and fibrosis.

Remarkably, deletion of $m i R-21 / m i R-21 *$ in hepatocytes (LImiR21KO mice) alters the ratio of lean and fat mass body composition and improves systemic glucose tolerance in mice fed with HFD. Although we did not investigated in details the mechanisms behind this phenotype, one attractive hypothesis is that deletion of $m i R-21 / m i R-21 *$ in hepatocytes triggers a crosstalk between the liver and other peripheral organs such as the adipose tissue, muscle or pancreas. Such crosstalk between liver and pancreas, mediated by liver-derived soluble factors, has been recently reported in mice having a liver-specific deletion of the insulin receptor [66] or a liver-specific deletion of PTEN.[37] In this regard, it is interesting to note that circulating levels of $m i R-21$ are increased in human patients with NAFLD [43] which may potentially impact the adipose tissue physiology. Indeed, recent studies reported a role for $m i R-21$ in adipocyte differentiation $[67,68]$. Whether circulating $m i R-21$ may promote insulin resistance and glucose intolerance in muscle or adipose tissue, thereby explaining the increased glucose tolerance observed in LImi21RKO mice fed a HFD, is currently unknown and under investigation.

Finally, future investigations should also shed light on the potential role of $m i R-21 / m i R-21 *$ in the progression of NAFLD toward more severe stages of liver disease and carcinogenesis and 
further delineate the potential of $m i R-21 / m i R-21 *$ as therapeutic targets for obesity-associated insulin resistance, NAFLD, NASH and cancer. 


\section{AUTHOR CONTRIBUTIONS}

N. Calo, P. Ramadori: study concept and design; acquisition, analysis and interpretation of data; drafting of the manuscript. C. Sobolewsky, C. Maeder, M. Fournier: acquisition, analysis and interpretation of data. Y. Romero, P. Rantakari, F. Zhang, M. Poutanen: acquisition of data. J.-F. Dufour, B. Humar: interpretation of data; critical revision of the manuscript for important intellectual content. S. Nef: analysis and interpretation of data; drafting of the manuscript; critical revision of the manuscript for important intellectual content; obtained funding. M. Foti: study concept and design; analysis and interpretation of data; drafting of the manuscript; critical revision of the manuscript for important intellectual content; obtained funding; study supervision. All authors critically revised the manuscript and approved its final version.

\section{CONFLICT OF INTEREST}

The authors have nothing to disclose.

\section{ACKNOWLEDGEMENTS}

We thank Prof. D. Metzger and Prof. P. Chambon (University of Strasbourg, France) for providing us with the $A l b$-cre- $E R^{T 2}$ mice. This work was supported by the Swiss National Science Foundation (grant $\mathrm{N}^{\circ} 31003 \mathrm{~A} 119862$ and 31003A 135227 to $\mathrm{SN}$ and $\mathrm{N}^{\circ} 310030$ 152618 and CRSII3-141798 and CRSII3-160717 to MF), The Bo \& Kerstin Hjelt Foundation and the EFSD Research Program in Diabetes and Cancer and the Swiss Cancer league (KFS02502-08-2009) to MF. 


\section{REFERENCES}

1 Anstee QM, Targher G, Day CP. Progression of NAFLD to diabetes mellitus, cardiovascular disease or cirrhosis. Nature reviews Gastroenterology \& hepatology 2013;10:330-44.

2 Attar BM, Van Thiel DH. Current concepts and management approaches in nonalcoholic fatty liver disease. TheScientificWorldJournal 2013;2013:481893.

3 Bensinger SJ, Christofk HR. New aspects of the Warburg effect in cancer cell biology. Semin Cell Dev Biol 2012;23:352-61.

4 Biswas S, Lunec J, Bartlett K. Non-glucose metabolism in cancer cells--is it all in the fat? Cancer Metastasis Rev 2012;31:689-98.

5 Rottiers V, Näär AM. MicroRNAs in metabolism and metabolic disorders. Nature reviews Molecular cell biology 2012;13:239-50.

6 Williams MD, Mitchell GM. MicroRNAs in insulin resistance and obesity. Experimental diabetes research 2012;2012:484696.

7 Lee S, Vasudevan S. Post-transcriptional stimulation of gene expression by microRNAs. Advances in experimental medicine and biology 2013;768:97-126.

8 Poy MN, Spranger M, Stoffel M. microRNAs and the regulation of glucose and lipid metabolism. Diabetes, obesity \& metabolism 2007;9 Suppl 2:67-73.

9 Ceccarelli S, Panera N, Gnani D, Nobili V. Dual Role of MicroRNAs in NAFLD. Int J Mol Sci 2013;14:8437-55.

10 Kaur K, Bhatia H, Datta M. MicroRNAs in hepatic pathophysiology in diabetes. World J Diabetes 2011;2:158-63.

11 Kerr TA, Korenblat KM, Davidson NO. MicroRNAs and liver disease. Transl Res 2011;157:241-52. 
12 Wong CM, Kai AK, Tsang FH, Ng IO. Regulation of hepatocarcinogenesis by microRNAs. Front Biosci (Elite Ed) 2013;5:49-60.

13 Pan X, Wang Z-X, Wang R. MicroRNA-21: a novel therapeutic target in human cancer. Cancer biology \& therapy 2010;10:1224-32.

14 Androsavich JR, Chau BN, Bhat B, Linsley PS, Walter NG. Disease-linked microRNA-21 exhibits drastically reduced mRNA binding and silencing activity in healthy mouse liver. RNA 2012;18:1510-26.

15 Adam O, Lohfelm B, Thum T, Gupta SK, Puhl SL, Schafers HJ, et al. Role of miR-21 in the pathogenesis of atrial fibrosis. Basic Res Cardiol 2012;107:278.

16 Liu G, Friggeri A, Yang Y, Milosevic J, Ding Q, Thannickal VJ, et al. miR-21 mediates fibrogenic activation of pulmonary fibroblasts and lung fibrosis. J Exp Med 2010;207:1589-97.

17 Patel V, Noureddine L. MicroRNAs and fibrosis. Curr Opin Nephrol Hypertens 2012;21:410-6.

18 Marquez RT, Bandyopadhyay S, Wendlandt EB, Keck K, Hoffer BA, Icardi MS, et al. Correlation between microRNA expression levels and clinical parameters associated with chronic hepatitis C viral infection in humans. Lab Invest 2010;90:1727-36.

19 Zhang J, Jiao J, Cermelli S, Muir K, Jung KH, Zou R, et al. miR-21 Inhibition Reduces Liver Fibrosis and Prevents Tumor Development by Inducing Apoptosis of CD24+ Progenitor Cells. Cancer Res 2015;75:1859-67.

20 Wang J, Gao Y, Ma M, Li M, Zou D, Yang J, et al. Effect of miR-21 on renal fibrosis by regulating MMP-9 and TIMP1 in kk-ay diabetic nephropathy mice. Cell Biochem Biophys 2013;67:537-46. 
21 Meng F, Henson R, Wehbe-Janek H, Ghoshal K, Jacob ST, Patel T. MicroRNA-21 regulates expression of the PTEN tumor suppressor gene in human hepatocellular cancer. Gastroenterology 2007;133:647-58.

22 Selaru FM, Olaru AV, Kan T, David S, Cheng Y, Mori Y, et al. MicroRNA-21 is overexpressed in human cholangiocarcinoma and regulates programmed cell death 4 and tissue inhibitor of metalloproteinase 3. Hepatology (Baltimore, Md) 2009;49:1595-601. 23 Francis H, McDaniel K, Han Y, Liu X, Kennedy L, Yang F, et al. Regulation of the extrinsic apoptotic pathway by microRNA-21 in alcoholic liver injury. J Biol Chem 2014;289:27526-39.

24 Wagenaar TR, Zabludoff S, Ahn SM, Allerson C, Arlt H, Baffa R, et al. Anti-miR-21 Suppresses Hepatocellular Carcinoma Growth via Broad Transcriptional Network Deregulation. Mol Cancer Res 2015;13:1009-21.

$25 \mathrm{Ng} \mathrm{R}$, Song G, Roll GR, Frandsen NM, Willenbring H. A microRNA-21 surge facilitates rapid cyclin D1 translation and cell cycle progression in mouse liver regeneration. The Journal of clinical investigation 2012;122:1097-108.

26 Yan-nan B, Zhao-yan Y, Li-xi L, jiang Y, Qing-jie X, Yong Z. MicroRNA-21 accelerates hepatocyte proliferation in vitro via PI3K/Akt signaling by targeting PTEN. Biochem Biophys Res Commun 2014;443:802-7.

27 Mah SM, Buske C, Humphries RK, Kuchenbauer F. miRNA*: a passenger stranded in RNA-induced silencing complex? Crit Rev Eukaryot Gene Expr 2010;20:141-8.

28 Ben-Dov IZ, Muthukumar T, Morozov P, Mueller FB, Tuschl T, Suthanthiran M. MicroRNA sequence profiles of human kidney allografts with or without tubulointerstitial fibrosis. Transplantation 2012;94:1086-94. 
fibroblast-derived microRNA passenger strand-enriched exosomes mediate cardiomyocyte hypertrophy. J Clin Invest 2014;124:2136-46.

30 Cheung O, Puri P, Eicken C, Contos MJ, Mirshahi F, Maher JW, et al. Nonalcoholic steatohepatitis is associated with altered hepatic MicroRNA expression. Hepatology 2008;48:1810-20

31 Vickers KC, Shoucri BM, Levin MG, Wu H, Pearson DS, Osei-Hwedieh D, et al. MicroRNA-27b is a regulatory hub in lipid metabolism and is altered in dyslipidemia. Hepatology (Baltimore, Md) 2013;57:533-42.

32 Vinciguerra M, Sgroi A, Veyrat-Durebex C, Rubbia-Brandt L, Buhler LH, Foti M. Unsaturated fatty acids inhibit the expression of tumor suppressor phosphatase and tensin homolog (PTEN) via microRNA-21 up-regulation in hepatocytes. Hepatology (Baltimore, Md) 2009;49:1176-84.

33 Morrisey EE. The magic and mystery of miR-21. J Clin Invest 2010;120:3817-9.

34 Schuler M, Dierich A, Chambon P, Metzger D. Efficient temporally controlled targeted somatic mutagenesis in hepatocytes of the mouse. Genesis 2004;39:167-72.

35 Jin X, Nowell CS, Ulyanchenko S, Stenhouse FH, Blackburn CC. Long-term persistence of functional thymic epithelial progenitor cells in vivo under conditions of low FOXN1 expression. PLoS One 2014;9:e114842.

36 Hameyer D, Loonstra A, Eshkind L, Schmitt S, Antunes C, Groen A, et al. Toxicity of ligand-dependent Cre recombinases and generation of a conditional Cre deleter mouse allowing mosaic recombination in peripheral tissues. Physiol Genomics 2007;31:32-41. 37 Peyrou M, Bourgoin L, Poher AL, Altirriba J, Maeder C, Caillon A, et al. Hepatic PTEN deficiency improves muscle insulin sensitivity and decreases adiposity in mice. $\mathrm{J}$ Hepatol 2015;62:421-9. 

the hepatic erythropoietin expression during acute-phase response: a role for IL-6. Laboratory investigation; a journal of technical methods and pathology 2010;90:1306-24.

39 Dweep H, Gretz N. miRWalk2.0: a comprehensive atlas of microRNA-target interactions. Nat Methods 2015;12:697.

40 Zhou J, Wang K-C, Wu W, Subramaniam S, Shyy JYJ, Chiu J-J, et al. MicroRNA-21 targets peroxisome proliferators-activated receptor-alpha in an autoregulatory loop to modulate flow-induced endothelial inflammation. Proceedings of the National Academy of Sciences of the United States of America 2011;108:10355-60.

41 Kida K, Nakajima M, Mohri T, Oda Y, Takagi S, Fukami T, et al. PPAR $\alpha$ is regulated by miR-21 and miR-27b in human liver. Pharmaceutical research 2011;28:2467-76.

42 Liu J, Liu W, Ying H, Zhao W, Zhang H. Analysis of microRNA expression profile induced by AICAR in mouse hepatocytes. Gene 2013;512:364-72.

43 Yamada H, Suzuki K, Ichino N, Ando Y, Sawada A, Osakabe K, et al. Associations between circulating microRNAs (miR-21, miR-34a, miR-122 and miR-451) and nonalcoholic fatty liver. Clin Chim Acta 2013;424C:99-103.

44 Wu H, Ng R, Chen X, Steer CJ, Song G. MicroRNA-21 is a potential link between non-alcoholic fatty liver disease and hepatocellular carcinoma via modulation of the HBP1p53-Srebp1c pathway. Gut 2015.

45 Ferland-McCollough D, Ozanne SE, Siddle K, Willis AE, Bushell M. The involvement of microRNAs in Type 2 diabetes. Biochem Soc Trans 2010;38:1565-70. 46 Guay C, Roggli E, Nesca V, Jacovetti C, Regazzi R. Diabetes mellitus, a microRNArelated disease? Transl Res 2011;157:253-64.

47 Szabo G, Bala S. MicroRNAs in liver disease. Nature reviews Gastroenterology \& hepatology 2013. 

Liver Dis 2015;35:12-25.

49 Go H, Jang JY, Kim PJ, Kim YG, Nam SJ, Paik JH, et al. MicroRNA-21 plays an oncogenic role by targeting FOXO1 and activating the PI3K/AKT pathway in diffuse large Bcell lymphoma. Oncotarget 2015;6:15035-49.

50 Larsen L, Rosenstierne MW, Gaarn LW, Bagge A, Pedersen L, Dahmcke CM, et al. Expression and localization of microRNAs in perinatal rat pancreas: role of miR-21 in regulation of cholesterol metabolism. PLoS One 2011;6:e25997.

51 Kim YJ, Hwang SH, Cho HH, Shin KK, Bae YC, Jung JS. MicroRNA 21 regulates the proliferation of human adipose tissue-derived mesenchymal stem cells and high-fat dietinduced obesity alters microRNA 21 expression in white adipose tissues. J Cell Physiol 2012;227:183-93.

52 Zhao J, Tang N, Wu K, Dai W, Ye C, Shi J, et al. MiR-21 simultaneously regulates ERK1 signaling in HSC activation and hepatocyte EMT in hepatic fibrosis. PLoS One 2014;9:e108005.

53 Loyer X, Paradis V, Henique C, Vion AC, Colnot N, Guerin CL, et al. Liver microRNA-21 is overexpressed in non-alcoholic steatohepatitis and contributes to the disease in experimental models by inhibiting PPARalpha expression. Gut 2015.

54 Chan SMH, Sun R-Q, Zeng X-Y, Choong Z-H, Wang H, Watt MJ, et al. Activation of PPAR $\alpha$ Ameliorates Hepatic Insulin Resistance and Steatosis in High Fructose-Fed Mice Despite Increased Endoplasmic Reticulum Stress. Diabetes 2013;62:2095-105.

55 Fan W, Imamura T, Sonoda N, Sears DD, Patsouris D, Kim JJ, et al. FOXO1 transrepresses peroxisome proliferator-activated receptor gamma transactivation, coordinating an insulin-induced feed-forward response in adipocytes. J Biol Chem 2009;284:12188-97. 
nuclear factor 4alpha coordinates a transcription factor network regulating hepatic fatty acid metabolism. Mol Cell Biol 2010;30:565-77.

57 Yecies JL, Zhang HH, Menon S, Liu S, Yecies D, Lipovsky AI, et al. Akt stimulates hepatic SREBP1c and lipogenesis through parallel mTORC1-dependent and independent pathways. Cell Metab 2011;14:21-32.

58 Connolly E, Melegari M, Landgraf P, Tchaikovskaya T, Tennant BC, Slagle BL, et al. Elevated expression of the miR-17-92 polycistron and miR-21 in hepadnavirus-associated hepatocellular carcinoma contributes to the malignant phenotype. Am J Pathol 2008;173:85664.

59 Orellana-Gavaldà JM, Herrero L, Malandrino MI, Pañeda A, Sol Rodríguez-Peña M, Petry $\mathrm{H}$, et al. Molecular therapy for obesity and diabetes based on a long-term increase in hepatic fatty-acid oxidation. Hepatology (Baltimore, Md) 2011;53:821-32.

60 Fukushima A, Loh K, Galic S, Fam B, Shields B, Wiede F, et al. T-cell protein tyrosine phosphatase attenuates STAT3 and insulin signaling in the liver to regulate gluconeogenesis. Diabetes 2010;59:1906-14.

61 Tripathy S, Jump DB. Elovl5 regulates the mTORC2-Akt-FOXO1 pathway by controlling hepatic cis-vaccenic acid synthesis in diet-induced obese mice. Journal of lipid research 2013;54:71-84.

62 Shimomura I, Matsuda M, Hammer RE, Bashmakov Y, Brown MS, Goldstein JL. Decreased IRS-2 and increased SREBP-1c lead to mixed insulin resistance and sensitivity in livers of lipodystrophic and ob/ob mice. Mol Cell 2000;6:77-86.

63 Ling HY, Hu B, Hu XB, Zhong J, Feng SD, Qin L, et al. MiRNA-21 reverses high glucose and high insulin induced insulin resistance in 3T3-L1 adipocytes through targeting phosphatase and tensin homologue. Experimental and clinical endocrinology \& diabetes: 
official journal, German Society of Endocrinology [and] German Diabetes Association 2012;120:553-9.

64 Ma X, Kumar M, Choudhury SN, Becker Buscaglia LE, Barker JR, Kanakamedala K, et al. Loss of the miR-21 allele elevates the expression of its target genes and reduces tumorigenesis. Proceedings of the National Academy of Sciences of the United States of America 2011;108:10144-9.

65 Wang B, Hsu S-H, Frankel W, Ghoshal K, Jacob ST. Stat3-mediated activation of microRNA-23a suppresses gluconeogenesis in hepatocellular carcinoma by down-regulating glucose-6-phosphatase and peroxisome proliferator-activated receptor gamma, coactivator 1 alpha. Hepatology (Baltimore, Md) 2012;56:186-97.

66 El Ouaamari A, Kawamori D, Dirice E, Liew CW, Shadrach JL, Hu J, et al. Liverderived systemic factors drive beta cell hyperplasia in insulin-resistant states. Cell Rep 2013;3:401-10.

67 Chartoumpekis DV, Zaravinos A, Ziros PG, Iskrenova RP, Psyrogiannis AI, Kyriazopoulou VE, et al. Differential expression of microRNAs in adipose tissue after longterm high-fat diet-induced obesity in mice. PloS one 2012;7:e34872.

68 Kang M, Yan LM, Zhang WY, Li YM, Tang AZ, Ou HS. Role of microRNA-21 in regulating 3T3-L1 adipocyte differentiation and adiponectin expression. Mol Biol Rep 2013. 


\section{FIGURE LEGENDS}

Figure 1. Adiposity and energy expenditure in CTRL and miR21KO mice fed a CD or HFD. (A) Body weight ( $n=9-10)$. (B) Fat and lean body mass by echo-MRI ( $n=4$ for CD, $n=9-10$ for HFD). (C) Food and water intake, (D) $\mathrm{O}_{2}$ consumption and $\mathrm{CO}_{2}$ production and (E) energy expenditure with the respective contributions of fat and carbohydrate/protein oxidation $(n=4)$.

Figure 2. Glucose/pyruvate tolerance and steatosis in CTRL and miR21KO mice. Glucose (A) and pyruvate (B) tolerance tests in CTRL and miR21KO mice fed a CD or HFD ( $\mathrm{n}=5$ for CD, $n=4-5$ for HFD). (C) Liver/body weight ratio and liver weight $(n=10)$ in mice fed a HFD. (D) Representative H\&E stained liver histological sections of mice fed a HFD. (E) Hepatic triglyceride (TG) and free/esterified cholesterol contents in mice fed a HFD (n=9).

Figure 3. Glucose metabolism and hepatic insulin sensitivity in CTRL and LImiR21KO mice fed a HFD. (A) Glucose and pyruvate tolerance tests (n=5). qRT-PCR (n=5) and Western blot analysis $(n=3)$ of the expression of hepatic genes/proteins involved in hepatic glycolysis (B) and gluconeogenesis (C). (D) Representative Western blots ( $n=3)$ and quantifications ( $n=5)$ of insulin signaling effectors in hepatic tissues. (E) Representative Western blots and quantifications $(n=4-5)$ of insulin-induced AKT phosphorylation in mouse primary hepatocytes isolated from CTRL and LImiR21KO mice fed a HFD.

Figure 4. Adiposity and hepatic lipid metabolism in CTRL and LImiR21KO mice fed a HFD. (A) Body weight, liver weight, and fat/lean body mass (Echo-MRI) $(n=5)$. (B) Representative $\mathrm{H} \& \mathrm{E}$ and Oil-red-O (ORO)-stained liver histological sections and quantifications of the lipid droplets (LDs) volumes extrapolated from the areas of ORO-stained LDs. Hepatic 
triglycerides (TG) and cholesterol esters/free cholesterol $(n=5)$. qRT-PCR analysis of the expression of hepatic genes involved in lipogenesis (C) and fatty acid uptake (D). (E) Representative Western blots analyses $(n=3)$ and quantifications $(n=5)$ of key effectors of the hepatic lipid metabolism.

Figure 5. Modulation of predicted and validated $m i R-21 / m i R-21 *$ targets regulating the hepatic lipid and glucose metabolism in CTRL and LImiR21KO mice fed a HFD. (A) Number of prediction softwares (out of 12 using miRwalk 2.0 Atlas) identifying metabolic genes targeted by $m i R-21(m i R-21-5 p)$, or $m i R-21 *(m i R-21-3 p)$. (B) Experimentally validated targets of miR-21 (miR-21-5p) investigated in this study. qRT-PCR analysis $(\mathrm{n}=5)$, representative Western blot $(n=3)$ and quantifications $(n=5)$ of transcriptional metabolic regulators, which are (C) potentially targeted directly by $m i R-21 / m i R-21^{*}$, or (D) under the control of potential $m i R-21 / m i R-21 *$ targets. (E) Hypothetical model of $m i R-21 / m i R-21 *_{-}$ dependent regulatory factors improving the hepatic lipid/glucose metabolism in LImiR21KO mice challenged with a HFD. 
A Body weight
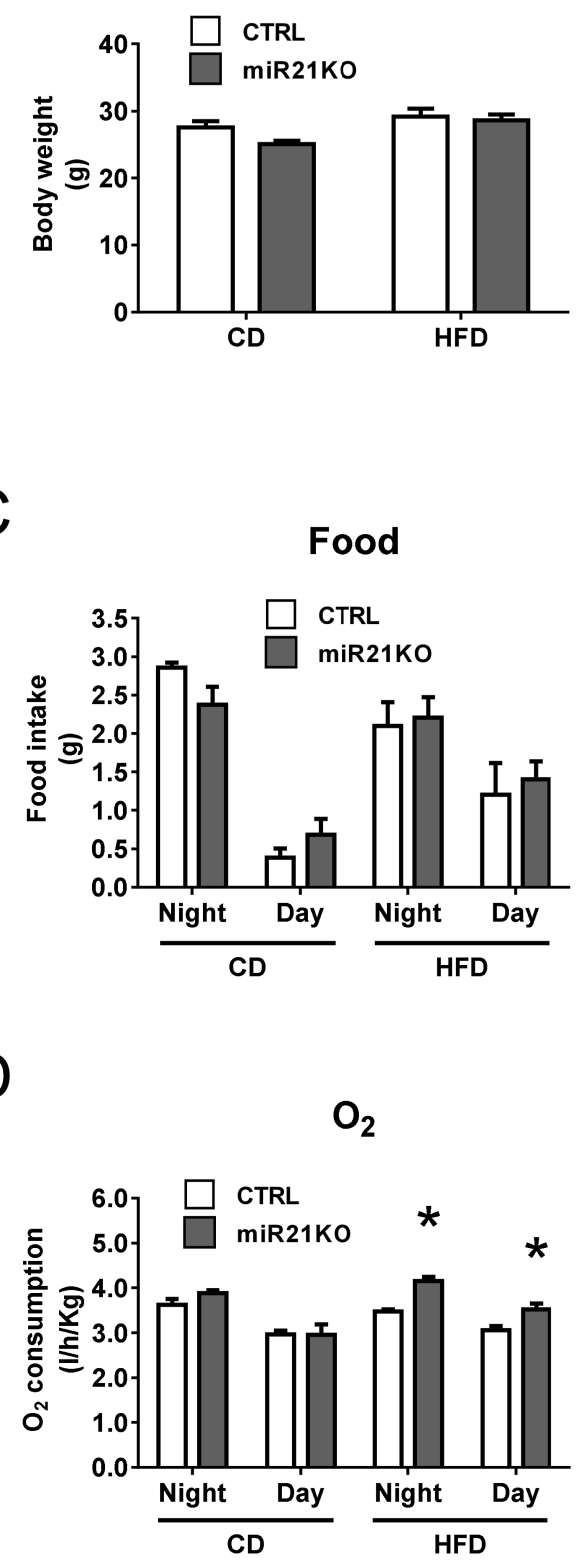

E

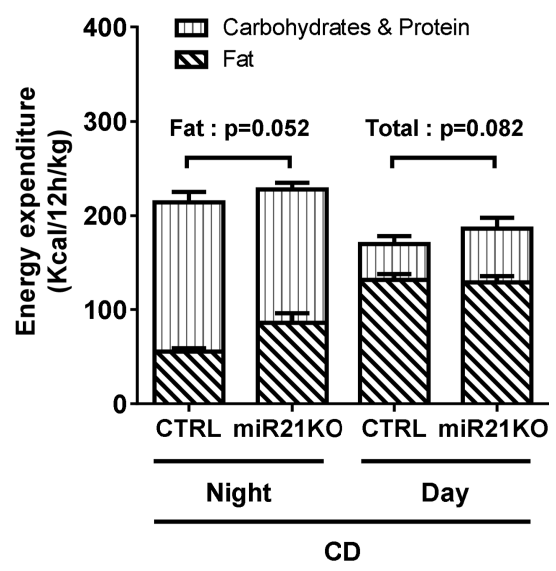

Food

D

C

\section{$\mathrm{O}_{2}$}

B ECHO-MRI

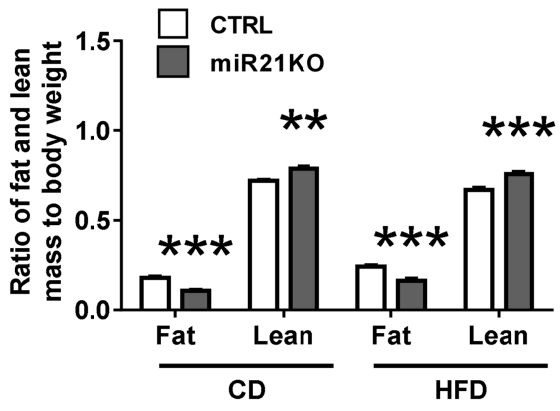

\section{Water}

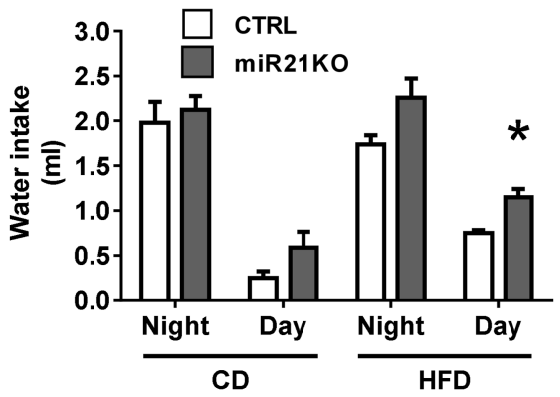

$\mathrm{CO}_{2}$
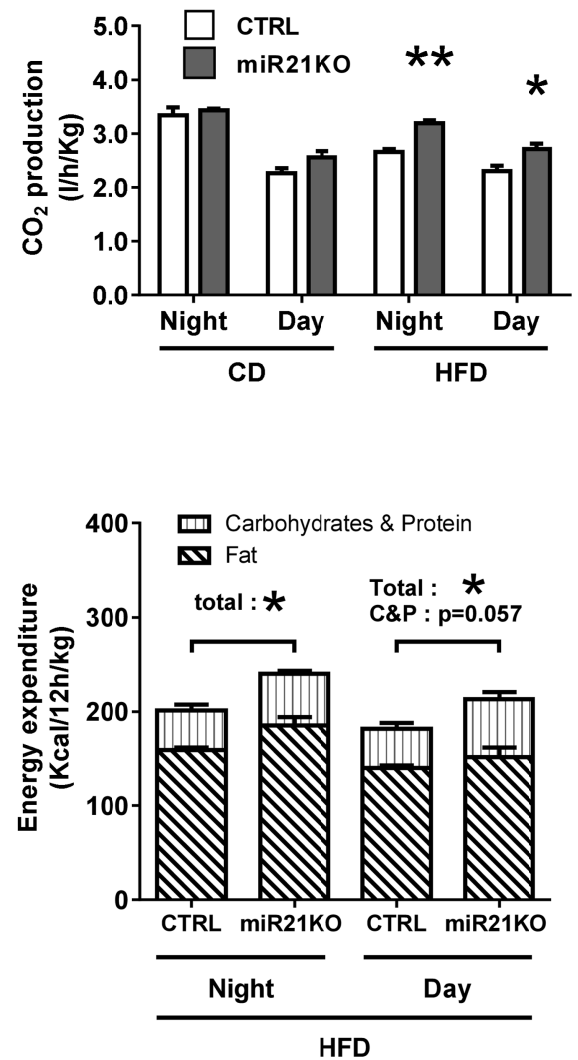

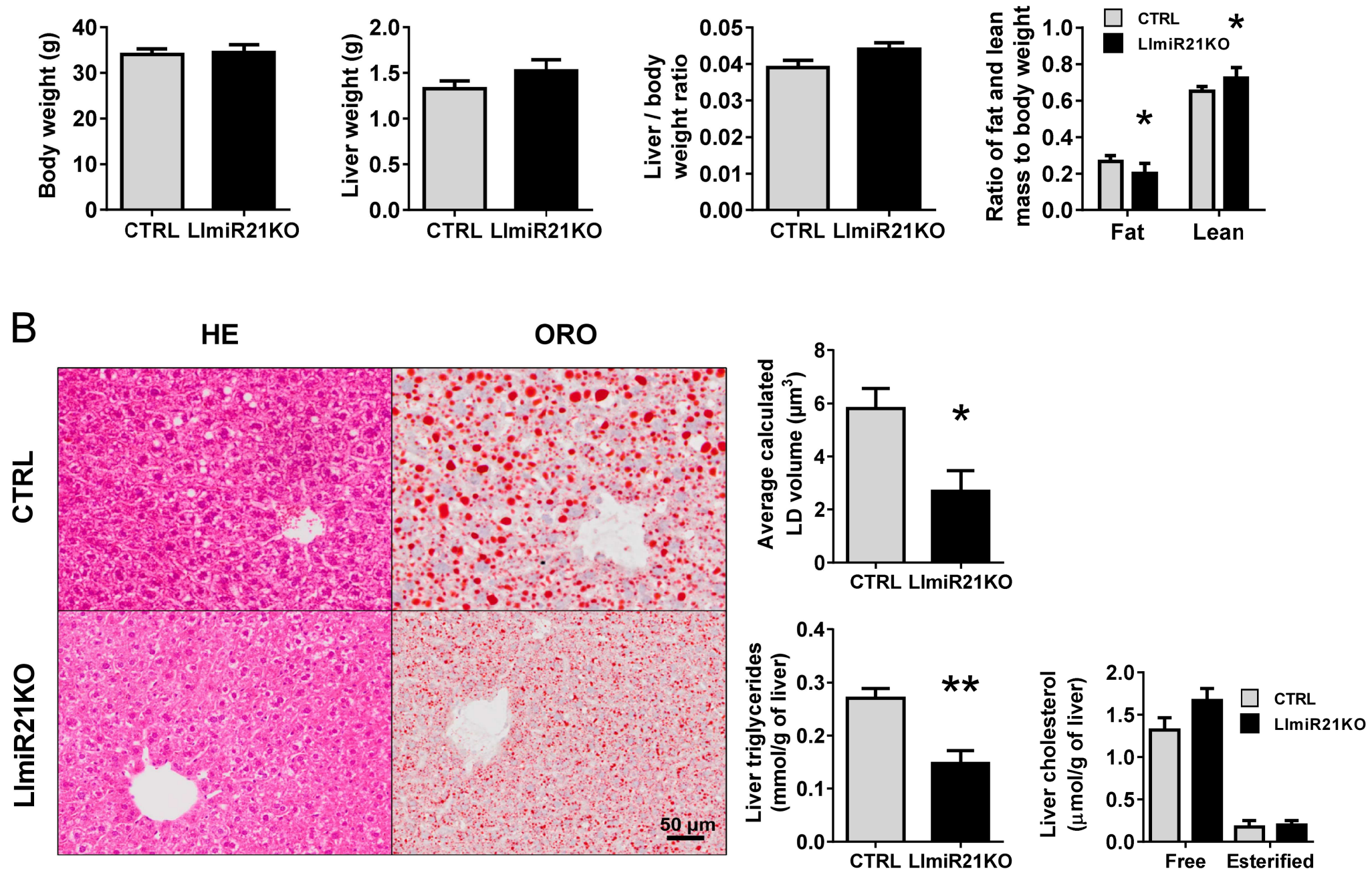

C

Lipogenesis

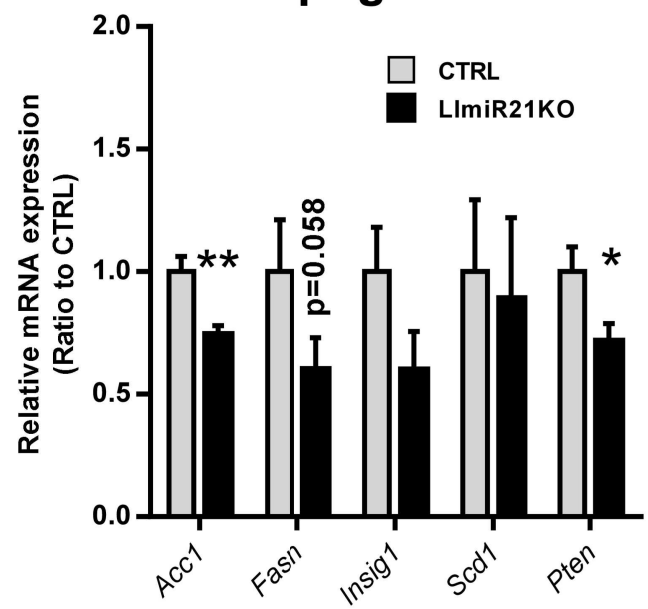

$\mathrm{E}$

CD36

FAS

ACC total

pACC total

(ser 79)

PTEN

ERM

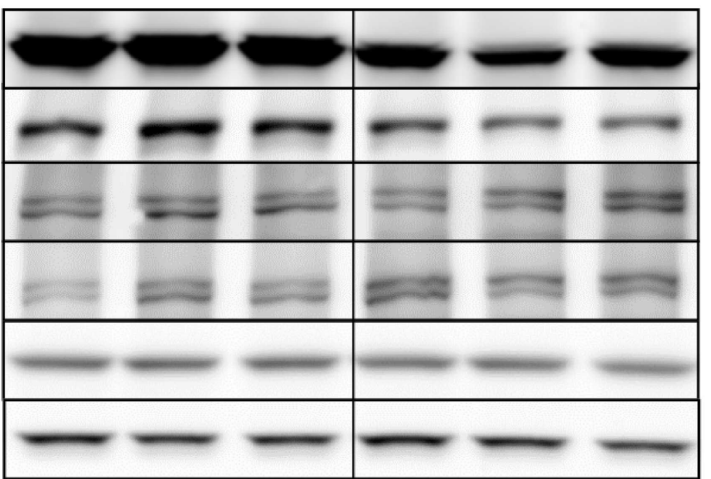

CTRL

LImiR21KO
D

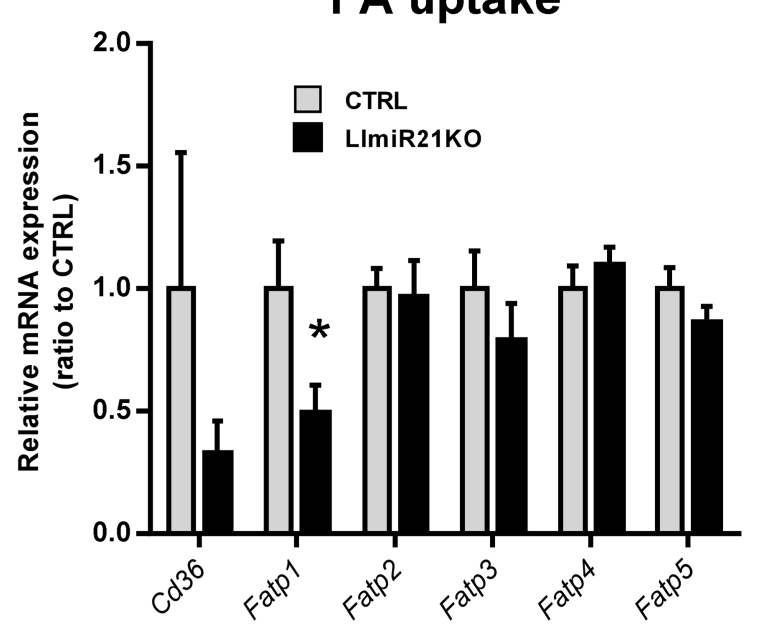

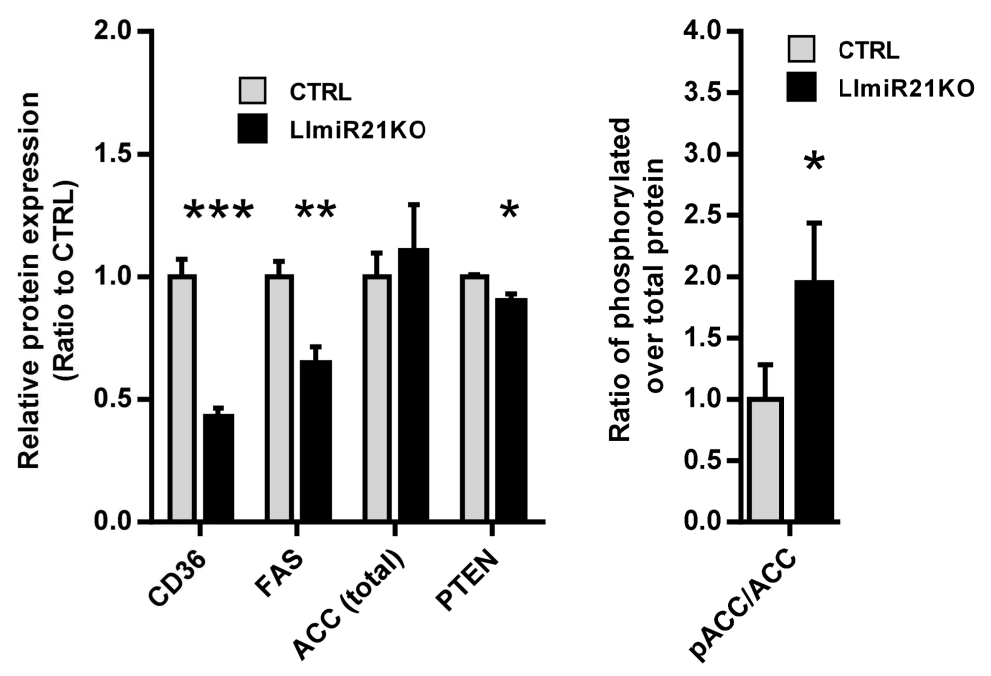


$A$

\begin{tabular}{|c|c|c|}
\hline miRNA & Target & $\begin{array}{c}\text { prediction } \\
\text { programs }\end{array}$ \\
\hline \multirow{5}{*}{ mmu-miR-21a-5p } & Acat1 & 9 \\
\cline { 2 - 3 } & Cyp7a1 & 7 \\
\cline { 2 - 3 } & Fabp2 & 7 \\
\cline { 2 - 3 } & Hnf4a & 9 \\
\cline { 2 - 3 } & Pdha1 & 8 \\
\cline { 2 - 3 } & Ppargc1a & 7 \\
\cline { 2 - 3 } & Stat3 & 8 \\
\hline
\end{tabular}

\begin{tabular}{|c|c|c|}
\hline miRNA & Target & $\begin{array}{c}\text { prediction } \\
\text { programs }\end{array}$ \\
\hline \multirow{5}{*}{ mmu-miR-21a-3p } & Cpt1a & 6 \\
\cline { 2 - 3 } & Foxa2 & 7 \\
\cline { 2 - 3 } & Hbp1 & 6 \\
\cline { 2 - 3 } & Hmgcr & 8 \\
\cline { 2 - 3 } & Insig2 & 8 \\
\cline { 2 - 3 } & Lipc & 6 \\
\cline { 2 - 3 } & Mgll & 6 \\
\cline { 2 - 3 } & Pdk1 & 7 \\
\cline { 2 - 3 } & Ppargc1a & 7 \\
\cline { 2 - 3 } & Pten & 7 \\
\cline { 2 - 3 } & Rictor & 6 \\
\cline { 2 - 3 } & Scd1 & 7 \\
\hline
\end{tabular}

B

\begin{tabular}{|c|c|c|c|c|}
\hline miRNA & Target & Organism & Model & PMID \\
\hline \multirow{18}{*}{ miR-21-5p } & \multirow{2}{*}{ FOXO1 } & HUMAN & PANC-1 & 25591761 \\
\hline & & HUMAN & A172 & 25232387 \\
\hline & HMGCR & HUMAN & HepG2 & 25605429 \\
\hline & Hbp1 & HUMAN & HepG2 & 26282675 \\
\hline & HNF4A & HUMAN & HEK293 Cells & 22140441 \\
\hline & PPARA & HUMAN & $\mathrm{HUH7}$ & 21562928 \\
\hline & \multirow{8}{*}{ PTEN } & \multirow{2}{*}{ HUMAN } & HepG2 & 19072831 \\
\hline & & & HepG2, HUH7, SMMC 7721 & 20447717 \\
\hline & & \multirow{2}{*}{ MOUSE } & Primary mouse mesangial cells & 19450585 \\
\hline & & & Cardiac fibroblasts & 19147652 \\
\hline & & \multirow{4}{*}{ RAT } & Glomerular Mesangium, Kidney Tubules, Proximal & 21613227 \\
\hline & & & Muscle, Smooth, Vascular & 21940949 \\
\hline & & & Endothelium, Vascular & 24562307 \\
\hline & & & HEK293, RVSMC & 24161401 \\
\hline & RXRA & HUMAN & Muscle, Smooth, Vascular, Pulmonary Artery, cos7 & 22158624 \\
\hline & \begin{tabular}{|l|} 
Srebf1 \\
\end{tabular} & RAT & INS-1E & 22022489 \\
\hline & \multirow{2}{*}{ STAT3 } & HUMAN & Mesenchymal Stromal Cells, Adipose Tissue & 21381024 \\
\hline & & MOUSE & ropnage & 25 \\
\hline
\end{tabular}

C
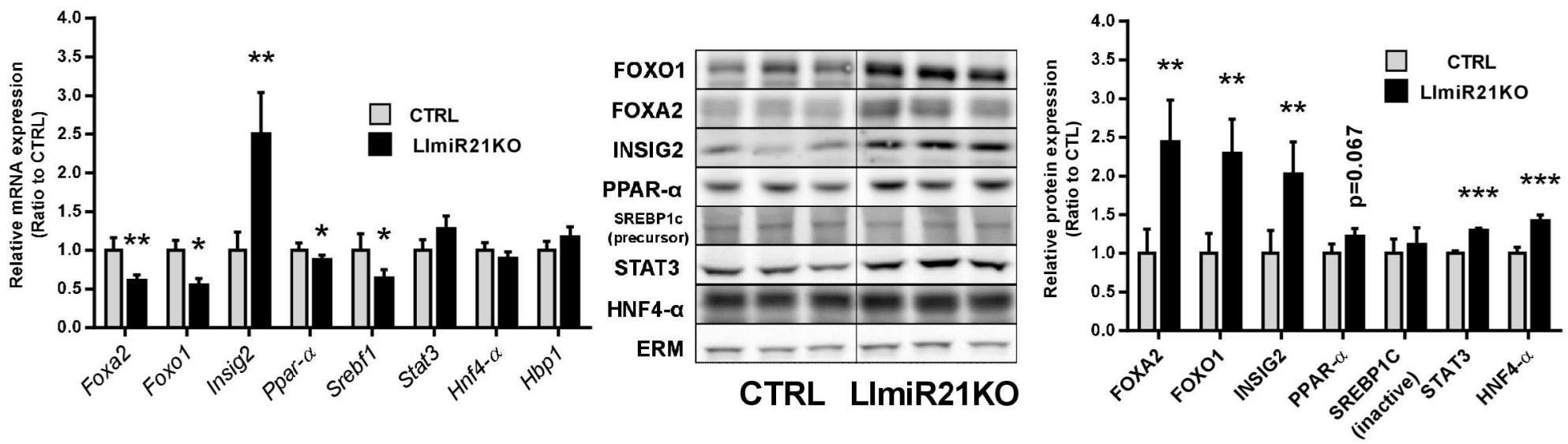

$D$

PF
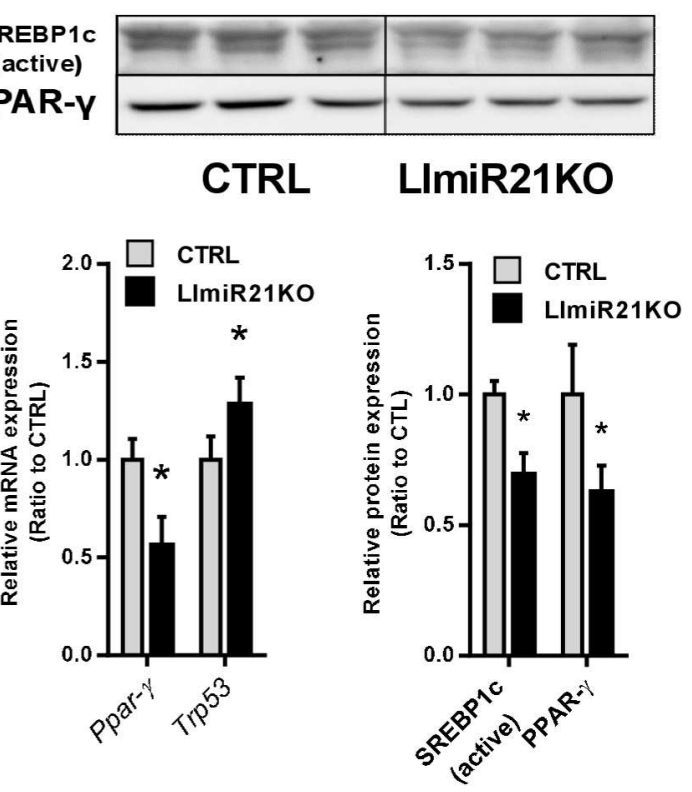

$E$

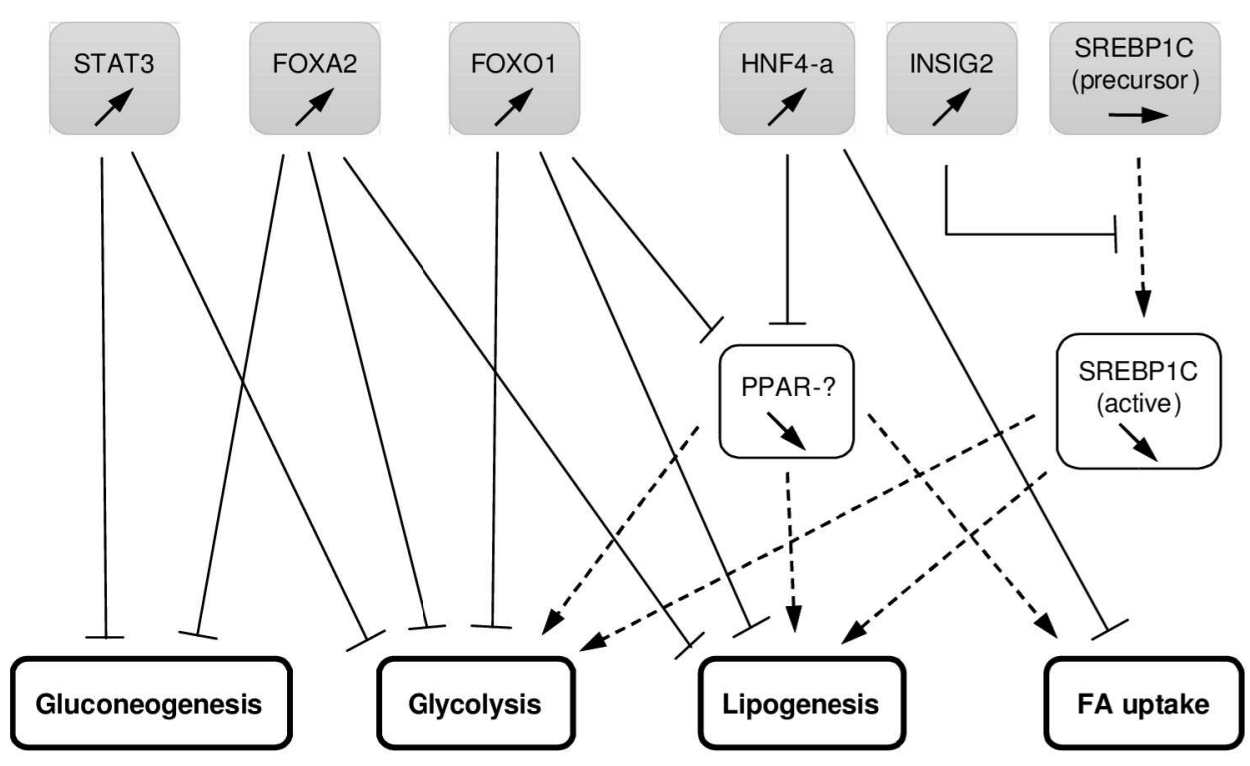

miR-21/miR-21* direct target 